\title{
A clinicopathological study of primary cutaneous amyloidosis
}

\author{
Kulkarni M. A. ${ }^{1}$, Patil T. ${ }^{2}$, Solanki P.S. ${ }^{3}$ \\ ${ }^{1}$ Dr. Madhavi A. Kulkarni, Assistant Professor, ${ }^{2}$ Dr. Tejeshwini Patil, Assistant Professor, ${ }^{3}$ Dr. Padma Shree Solanki, \\ Third Year, Post Graduate Student; all authors are attached with Department of Pathology, Navodaya Medical College, \\ Raichur, Karnataka, India.
}

Corresponding Author: Dr. Tejeshwini Patil, Assistant Professor, Department of Pathology, Navodaya Medical College, Raichur, Karnataka, India. E-mail: tejeshwinimd@gmail.com

\begin{abstract}
Background: Primary localized cutaneous amyloidosis (PCA) is a common problem encountered in dermatology outpatient characterized by deposition of amyloid in dermis without any systemic involvement. Three subtypes have been recognized namely Macular, Papular (Lichen) and Nodular forms. Histopathological examination of the lesions reveals amorphous eosinophilic deposits in papillary dermis which stain positively with congo red. Aim: To study and correlate the clinical and histological profile of all three forms of primary cutaneous amyloidosis. Materials and Methods: A total number of 85 cases of primary cutaneous amyloidosis were included in the study. After a detailed history and complete examination, the patient was subjected to skin biopsy from the affected area. The clinical and histopathological findings obtained were analyzed and results correlated. Results: Of the 85 cases of Primary localized cutaneous amyloidosis, 43 cases $(50.6 \%)$ were of Lichen amyloidosis and 36 cases $(42.35 \%)$ were Macular amyloidosis. 6 cases (7\%) were biphasic amyloidosis. Most of patients were in the age group of 21-50 years with slight female predominance 1:1.3. Majority of the cases of Lichen amyloidosis involved the pretibial area where as Macular amyloidosis affected the upper back and extensor aspect of arms. Histopathologically, the epidermis showed hyperkeratosis and irregular acanthosis which was more prominent finding in Lichen amyloidosis than the macular form. In both these variants there was expansion of dermal papillae by amyloid deposits showing positive congo red staining. Conclusions: Similar demographic profile and histopathological characteristics between Lichen and Macular amyloidosis suggests that these two forms are closely related variants of a single disease.
\end{abstract}

Key words: Congo red stain, Lichen amyloidosis, Macular amyloidosis

\section{Introduction}

Amyloid refers to extra cellular abnormal fibrous, proteinaceous deposits that are resistant to proteolytic digestion. These deposits can be localized or can be systemic, involving several organs and tissues [1]. In primary localized cutaneous amyloidosis, amyloid is deposited in an apparently normal skin with no evidence of deposits occurring in internal organs. The etiology is unknown [2].

Three forms of primary cutaneous amyloidosis (PCA) are known: macular amyloidosis (MA), lichen amyloidosis (LA) and nodular amyloidosis (NA) [3]. Biphasic amyloidosis (BA) is relatively rare and characterized by presence of concurrent lesions of both macular and lichen amyloidosis. Lichen amyloidosis and macular amyloidosis can be considered as a same disease process with different clinical manifestations.

Manuscript received: $4^{\text {th }}$ June 2019

Reviewed: $10^{\text {th }}$ June 2019

Author Corrected: $16^{\text {th }}$ June 2019

Accepted for Publication: $20^{\text {th }}$ June 2019
Lichen amyloidosis is characterized by severely itchy, discrete, scaly, reddish brown papules most commonly located on the shins, although can occur elsewhere also. These papules may coalesce to form plaques [1]. Lichen amyloidosis is most frequently seen in Southeast Asia, China, and South America [4]. Most often the cause is idiopathic and related to chronic friction due to pruritus which leads to damage of keratinocytes and subsequent production of amyloid [1].

Macular amyloidosis is characterized by small brownish pruritic eruptions mostly distributed symmetrically on the upper back, but can occur anywhere on the trunk or extremities. Various risk factors like race, female gender, genetic predisposition, atopy and sun exposure have been implicated in its etiopathogenesis [1].

Nodular amyloidosis is a rare condition seen as single or multiple pink to yellowish brown nodules on face, extremities, trunk or genitalia.

Pathology Update: Tropical Journal of Pathology \& Microbiology Available online at: www.medresearch.in 396 | P a g e 


\section{Original Research Article}

In lichen and macular amyloidosis the amyloid deposits are usually confined to the papillary dermis and do not involve blood vessels or adnexal structures. In nodular amyloidosis, amyloid deposits are found in the entire dermis, often involving blood vessels as well as the subcutaneous tissue.

The amyloid in lichen and macular amyloidosis is derived from the filamentous degeneration of keratinocytes and hence called $\mathrm{K}$ amyloid whereas in nodular amyloidosis, the amyloid fibrils are derived from immunoglobulin light chains and are therefore of AL type [3].

Thus it is important to study and correlate the clinical forms and their histopathological features which help in planning the correct treatment of cutaneous amyloidosis.

\section{Materials and Methods}

Place and type of study: It is a prospective study conducted over a period of 2 years from January 2017 to December 2018. A total number of 85 patients attending the Dermatology OPD at Navodaya Medical College Hospital and Research Centre, Raichur, Karnataka were included in the study. A detailed analysis of clinical history, examination findings and histopathological findings were done.
Sampling methods and sample collection: A detailed history regarding duration of illness, progression, precipitating factors and family history was noted. A detailed clinical examination regarding the location and type of lesions was done followed by all other necessary laboratory investigations. Patients were subjected to skin biopsy after obtaining a written consent.

After taking aseptic precautions, the biopsy site was infiltrated with $2 \%$ lignocaine. An elliptical incision along the skin lines was made and a full thickness skin biopsy of $2 \mathrm{~cm}$ size was taken and preserved in $10 \%$ formalin. The labeled biopsy specimen was received in the Department of Pathology, Navodaya Medical College. Routine paraffin processing and HematoxylinEosin (H\&E) staining were done.

Special stains like PAS, Congo red were used wherever necessary. After obtaining the Histopathology reports, the clinical and histopathological findings were tabulated.

Inclusion criteria: Patients belonging to both the sexes and all the age groups were included in the study.

Exclusion criteria: Patients who did not give consent for skin biopsy were excluded.

\section{Results}

Eighty five skin biopsies with a clinical diagnosis of primary cutaneous amyloidosis were received in the department of pathology between January 2017 and December 2018. In the present study, out of 85 patients, 37 (43.53\%) were males and $48(56.47 \%)$ were females with a male to female ratio of 1:1.3. The age incidence ranged from 15 to 70 years with a mean age of 43.04 years.

The duration of the lesions ranged from 2 months to 30 years. $28(32.94 \%)$ patients were asymptomatic and rest 57 $(67.06 \%)$ had pruritis as a presenting symptom. Pretibial area and upper back were the commonest sites of involvement [Figure 1]. The other sites of involvement were extensor aspect of arm and forearm, lower back, buttocks, neck and shoulders. Lichenified papules were seen in 43 patients, pigmented macules in 21 cases and lichenified papules with pigmented macules in 6 patients.

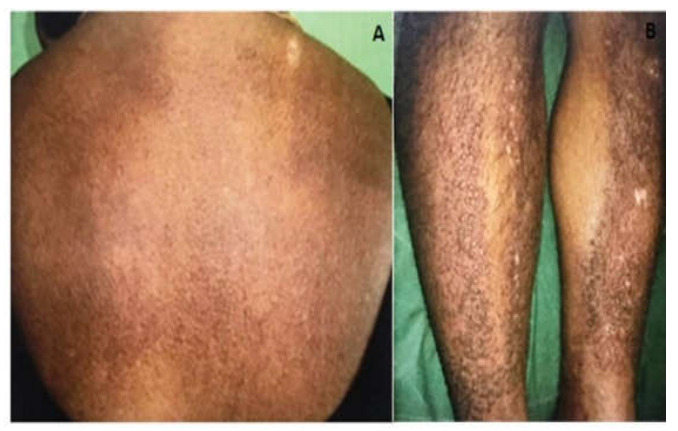

Figure-1: A. Macular Amyloidosis on upper back region showing rippled pattern B. Lichen Amyloidosis over pretibial area. (Bilateral). 


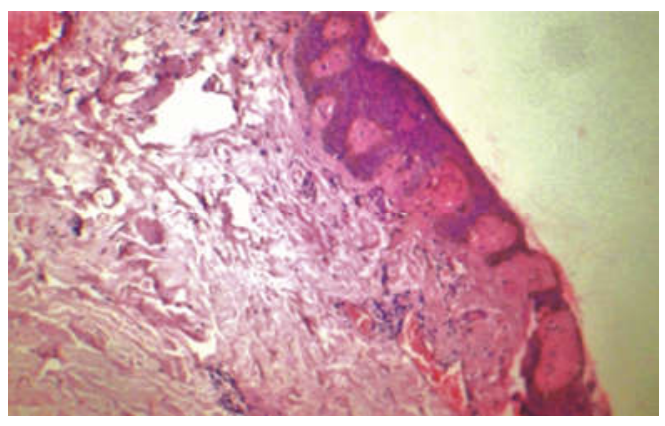

Original Research Article

Figure-2: Photomicrograph of Macular Amyloidosis showing rounded eosinophilic amyloid in upper papillary dermis (H \& E stain-100x).

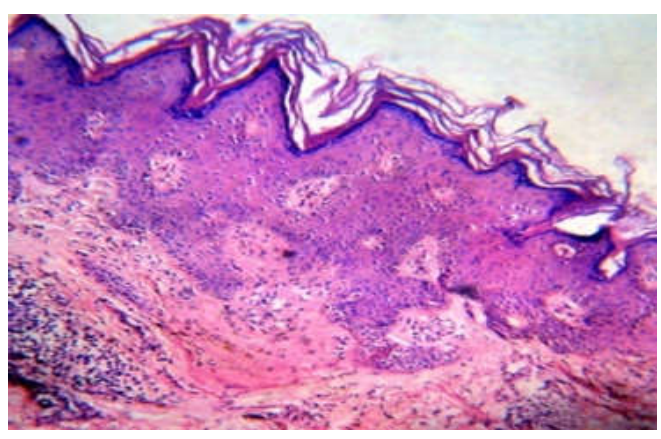

Figure-3: Photomicrograph of Lichen Amyloidosis with amyloid in papillary dermis (H \& E stain-100x).

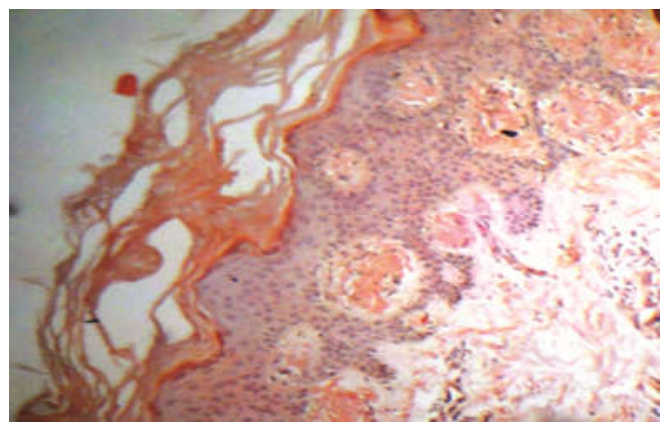

Figure-4: Photomicrograph of Congo red stain section of Lichen Amyloidosis with red coloured amyloid masses in papillary dermis (H \& E stain-100x).

Among 85 skin biopsies, the majority of cases were of lichen amyloidosis followed by macular and biphasic amyloidosis [Table 1].

Table-1: Types of cutaneous amyloidosis.

\begin{tabular}{|c|c|c|}
\hline Clinical types & No. of patients & Percentage \\
\hline Lichen amyloidosis & 43 & 50.58 \\
\hline Macular amyloidosis & 36 & 42.35 \\
\hline Biphasic amyloidosis & 6 & 7.05 \\
\hline Total & $\mathbf{8 5}$ & $\mathbf{1 0 0}$ \\
\hline
\end{tabular}

Histopathological examination of H\&E stained sections showed basal cell pigmentation, with mild hyperkeratosis, acanthosis and papillomatosis in cases of macular amyloidosis [Figure 2]. In patients of lichen amyloidosis, acanthosis and hyperkeratosis were prominent features followed by basal cell pigmentation, papillomatosis and hypergranulosis [Figure 3] [Table 2]. 
Table-2: Epidermal changes in different forms of cutaneous amyloidosis.

Original Research Article

\begin{tabular}{|c|c|c|c|c|c|c|c|c|}
\hline \multirow[t]{2}{*}{ Epidermal changes } & \multicolumn{2}{|c|}{$\begin{array}{c}\text { Cutaneous } \\
\text { amyloidosis }\end{array}$} & \multicolumn{2}{|c|}{ MA } & \multicolumn{2}{|c|}{$\mathbf{L A}$} & \multicolumn{2}{|c|}{ BA } \\
\hline & No. & $\%$ & No. & $\%$ & No. & $\%$ & No. & $\%$ \\
\hline Hyperkeratosis & 64 & 75.29 & 23 & 63.33 & 36 & 83.72 & 5 & 83.33 \\
\hline Acanthosis & 55 & 64.70 & 12 & 33.33 & 37 & 86.04 & 6 & 100.00 \\
\hline Hypergranulosis & 14 & 16.47 & 0 & 0 & 10 & 23.25 & 4 & 66.66 \\
\hline Papillomatosis & 35 & 41.17 & 7 & 19.44 & 24 & 55.81 & 4 & 66.66 \\
\hline Basal cell pigmentation & 65 & 76.47 & 25 & 69.45 & 35 & 81.39 & 5 & 83.33 \\
\hline
\end{tabular}

The dermal changes observed were amyloid deposits in the papillary dermis, pigmentary incontinence and lymphohistiocytic infiltrate [Table 3].

Table-3: Dermal changes in different forms of cutaneous amyloidosis.

\begin{tabular}{|l|c|c|c|c|c|c|c|c|}
\hline Dermal changes & \multicolumn{2}{|c|}{ Total } & \multicolumn{2}{c|}{ MA } & \multicolumn{2}{c|}{ LA } & \multicolumn{2}{c|}{ BA } \\
\hline & No. & \% & No. & \% & No. & \% & No. & \% \\
\hline Amyloid & 76 & 89.41 & 30 & 83.33 & 40 & 93.02 & 6 & 100.00 \\
\hline $\begin{array}{l}\text { Pigmentary } \\
\text { incontinence }\end{array}$ & 49 & 57.64 & 20 & 55.55 & 25 & 58.14 & 4 & 66.66 \\
\hline $\begin{array}{l}\text { Lymphohistiocytic } \\
\text { infiltrate }\end{array}$ & 83 & 97.64 & 36 & 100.00 & 41 & 95.34 & 6 & 100.00 \\
\hline
\end{tabular}

These deposits on Congo Red stain appeared as reddish orange substance [Figure 4]. Visualization under polarized light, the congo red stained deposits showed apple-green birefringence, confirming the presence of amyloid. No case of nodular amyloidosis was observed in the present study.

\section{Discussion}

Rokintansky gave the first description of amyloidosis in 1842 and the term Amyloid (starch like) was originally coined in 1854 by Virchow [5,6]. It involves extracellular deposition of a proteinaceous substance belonging to family of biochemically unrelated proteins, depending on the underlying condition and which is usually associated with considerable tissue dysfunction [7].

Amyloidosis can be systemic or localized [5]. Cutaneous amyloidosis was first reported by Gutmann in 1928 [8]. Primary localized cutaneous amyloidosis is defined as localized uncontrolled deposition of amyloid in the epidermis and dermis without evidence of systemic involvement. It can be of 3 clinical types: Lichen amyloidosis, Macular amyloidosis and Nodular or tumefactive amyloidosis. Macular being the most common and nodular being a rare form. Macular and papular forms may co-exist in the same patients; this is known as biphasic amyloidosis [5].

Secondary cutaneous amyloidosis as described by Lubarsch in 1929 is characterized by the presence of amyloid in the stroma of various cutaneous tumors such as basal cell carcinoma, squamous cell carcinoma, nevi and few adnexal tumours [6]. It can also be seen in seborrheic and actinic keratosis, Bowen's disease, porokeratosis, therapeutic UVA radiation [6]. Lichenoid amyloidosis can arise in a setting of macular amyloidosis, presumably due to scratching. When treated by intralesional injection of steroids, the lichenoid lesions can become macular [1].

Freudenthal, in 1930, introduced the term "lichen amyloidosis"[8]. It is seen most frequently in South East Asia, China, and South America. Its etiology is unknown but chronic irritation (scratching) to the skin has been proposed as an etiological factor [6]. History of scrubbing while taking bath was given by $90.58 \%$ patients in the present study which is consistent with that of Salim T et al (56.7\%) [5]. Amyloid fibrils have a beta pleated sheet configuration and contain disulfide bonds, which are present in keratin [9]. Hashimoto's "Fibrillar body theory" proposes that the tonofilaments of keratinocytes undergo filamentous degeneration and drop off into the dermis where they are modified into amyloid material [10]. Secretion theory of Yamagehara et al suggests that the amyloid in macular amyloidosis 
Original Research Article

may be secreted by disrupted basal cells which deposits at the dermo-epidermal junction [11]. The amyloid in lichen and macular amyloidosis is derived from the keratinocytes and hence called $\mathrm{K}$ amyloid. Nodular amyloidosis is considered as a cutaneous plasmacytoma, locally producing immunoglobulin light chains as precursor to AL type fibril proteins and there is no specific staining with anti-keratin antibodies [11].

In the present study, LA was the most common variant with $50.58 \%$ incidence, macular amyloidosis accounting for $42.35 \%$ and bi-phasic amyloidosis $7 \%$. These findings are in concurrence with the study by Looi et al with $74 \%$ cases of Lichen Amyloidosis and $26 \%$ of Macular amyloidosis [12]. In the study by Wang et al, out of 794 cases, $67 \%$ of cases were of Lichen Amyloidosis and 26\% of Macular amyloidosis. $25 \%$ cases showed biphasic amyloidosis [13]. But in the study by Al-Ratrout and Satti M.B., most cases (90\%) were of Macular amyloidosis and only $10 \%$ of the cases were of Lichen Amyloidosis [14].

In the present study, it was found that a female preponderance with male to female ratio being 1:1.3. The mean age of involvement was 43.04 years. The mean age of cutaneous amyloidosis in the present study is close to the studies of Looi et al (39 years) and AlRatrout and Satti M.B (37.19 years) [12, 14]. The disease duration ranged from 2 months to 30 years with the most common presenting complain of pruritus.

Macular amyloidosis commonly involved the upper back, followed by extensor aspect of arm and forearm and pretibial region, while Lichen amyloidosis most frequently involved the pretibial region $(86 \%)$.

The dermal changes seen in macular amyloidosis and lichen amyloidosis were almost the same, with deposits of amyloid limited to the papillary dermis and not involving blood vessels or adnexal structures associated with lymphohistiocytic inflammatory infiltrates and pigment incontinence.

The epidermis was less frequently involved in macular amyloidosis and showed acanthosis (33.33\%), hyperkeratosis $(63.33 \%)$, basal cell pigmentation (69.45\%) and mild papillomatosis (19.44\%). Al-Ratrout and Satti M.B in their study observed normal epidermis and only $10 \%$ of the cases showed focal basal cell degeneration [14]. Black M.M. and Jones E.W. found epidermal changes in $50 \%$ of cases which showed moderate acanthosis, hyperkeratosis and elongation of rete ridges [10]. Both these studies showed dermal perivascular lymphohistiocytic infiltrates and melanin incontinence which was also noted in the present study.
In LA the amyloid deposits are larger often displacing the elongated rete ridges laterally and is accompanied by marked irregular acanthosis( $86.04 \%)$, hyperkeratosis $(83.72 \%)$, papillomatosis $(55.81 \%)$, hypergranulosis $(23.25 \%)$ and pigmentation of basal cells of the overlying epidermis. In nodular amyloidosis, amyloid deposits are found in the entire dermis, often involving blood vessels and subcutaneous tissue. Similar features were also noted in the studies done by Al-Ratrout and Satti M.B, Black M.M. and Jones E.W. and Looi et al.

In biphasic amyloidosis, acanthosis was seen in all patients $(100 \%)$ followed by hyperkeratosis and basal cell pigmentation each $(83.33 \%)$, hypergranulosis and papillomatosis in each $(66.66 \%)$. Dermal changes were: amyloid was present in $100 \%$, pigmentary incontinence in $66.67 \%$ and lymphohistiocytic infiltrate in $100 \%$.

In nodular amyloidosis, large masses of amyloid are deposited in papillary dermis, reticular dermis and subcutaneous fat. It is also seen in vessel walls and eccrine glands.

Amyloid appears as homogenous, hyaline, eosinophilic deposits in H\&E stained sections. It shows a positive staining with Congo red and gives an apple green birefringence under polarized light. It appears as fibrillar structure on electron microscopy [10]. On direct immunofluorescence, all specimens of lichen or macular amyloidosis fluoresce positively for immunoglobulins or complement, particularly IgM and C3. Staining for kappa and lambda light chains is positive [15] Antikeratin antibodies that label keratins are useful in detecting primary cutaneous amyloidosis. Immunostains for light chain deposition aid in the diagnosis of nodular amyloidosis [10].

In the present study out of 85 clinically diagnosed cases of cutaneous amyloidosis, in 9 patients amyloid was not detected in the biopsies. In these cases as observed by Black M.M., the amyloid deposits can probably be demonstrated in subsequent biopsies [10].

The primary differential diagnosis for lichen amyloidosis is lichen simplex chronicus and hypertrophic lichen planus. Histologically, both have hyperkeratosis, acanthosis and a mild to moderate lymphohistiocytic inflammatory infiltrate but no amyloid deposits. Macular amyloidosis can be confused with ichthyosis, stasis dermatitis, pigmented purpuric eruptions of the lower extremities and post inflammatory hyper pigmentation $[16,10]$. The lesions of nodular amyloidosis may resemble those seen in primary systemic amyloidosis, but extracutaneous sites are not infiltrated with amyloid [10]. 


\section{Conclusion}

Primary cutaneous amyloidosis is one of the common dermatological and cosmetic problems encountered. In general the treatment of cutaneous amyloidosis is prolonged and unsatisfactory. It needs to be differentiated from various other clinical mimickers which can be resolved by Histopathological study.

The diagnosis of primary cutaneous amyloidosis can made on $\mathrm{H}$ and $\mathrm{E}$ stained sections but is confirmed by apple green birefringence under polarized light after Congo red staining. Similar demographic profile and histopathological characteristics between Lichen and Macular amyloidosis suggests that the two forms of primary localized cutaneous amyloidosis are closely related variants of a single disease.

\section{Contribution details}

Dr. Madhavi Kulkarni and Dr. Tejeshwini Patil finalized the study concept, design, acquisition of data, analysis and interpretation of data, compilation of literature sources, drafting of the manuscript, crosschecking of references along with clinical revision, whereas Dr. Padma Shree Solanki finalized literature compilation and cross-checking of references.

What This Study Adds To Existing KnowledgeReview of literature from previous studies and the present study show the increasing incidence of primary localized cutaneous amyloidosis and the various close clinical differential diagnoses warrants skin biopsy and histopathological examination to confirm the presence of amyloid. The similar histopathological features of macular and lichen amyloidosis suggests a single disease process with varied clinical manifestations.

Findings: Nil; Conflict of Interest: None initiated Permission from IRB: Yes

\section{References}

1. Maize J, Maize Jr J, Metcalf J. Metabolic Diseases of the Skin. In: Elder, David E, Elenitsas R, Johnson, Bernett L,Murphy, et al, editors.Lever's Histopathology of the Skin, 9th ed. Philadelphia: Lippincott Williams and Wilkins; 2004. p. 436-41.

2. Shah MP, Padhiar B, Karia U. Primary cutaneous amyloidosis. Indian J Dermatol Venereol Leprol. 1997; 63 (2):105-6.

3. Li WM. Histopathology of primary cutaneous amyloidoses and systemic amyloidosis. Clin Dermatol. 1990;8(2):30-5.DOI:https://doi.org/ 10.1016/ 0738081X(90)90085-F

\section{Original Research Article}

4. Behr FD, Levine N, Bangert J. Lichen amyloidosis associated with atopic dermatitis: clinical resolution with cyclosporine. Arch Dermatol. 2001; 137 (5):553-5. DOI: 10-1001/pubs.Arch Dermatol.-ISSN-0003-987x137-5-dce 10007.

5. Salim T, Shenoi SD, Balachandran C, Mehta VR. Lichen amyloidosus: a study of clinical, histopathologic and immunofluorescence findings in 30 cases. Ind $\mathrm{J}$ Dermatol, Venereol, and Leprol. 2005; 71 (3): 166. DOI: $10.4103 / 0378-6323.16230$

6. Rubinow A, Cohen AS. Skin involvement in generalized amyloidosis. A study of clinically involved and uninvolved skin in 50 patients with primary and secondary amyloidosis. Ann Intern Med. 1978 Jun;88 (6): 781-5. DOI: 10.7326/0003-4819-88-6-781

7. Steciuk A, Dompmartin A, Troussard X, Verneuil L, Macro M, Comoz F. et al Cutaneous amyloidosis and possible association with systemic amyloidosis. Int $\mathrm{J}$ Dermatol. 2002;41(3):127-32. DOI: https://doi.org/10. 1046/j. 1365-4362.2002.01411.x

8. Wong CK. History and modern concepts. Clin Dermatol. 1990; 8(2):1-6. DOI: https://doi.org/10.1016/ 0738-081X(90)90080-K

9. Lachmann H, Hawkins NP. Amyloidosis and the skin. In: Wolff K, Goldsmith LA, Katz SI, Gilchrest BA, Paller AS, Leffell DJ. Eds. Fitzpatrick's Dermatology in General Medicine: $7^{\text {th }}$ edn Vol.2, United States of America:The McGraw-Hill companies. Inc, 2008.p. 1257-1264.

10. Black MM, Albert S, Upjohn E Amyloidosis. In: Bolognia JL, Jorizzo JL, Rapini RP, eds. Dermatology: $2^{\text {nd }}$ edn Vol I, Philadelphia: Mosby, 2008. P.659-667.

11. Touart DM, Sau P. Cutaneous deposition diseases. Part I. J Am Acad Dermatol. 1998 Aug; 39 (2 Pt 1): 149-71; quiz 172-4. DOI: 10.1016/s0190-9622 (98) 70069-6

12. Looi LM. Primary localised cutaneous amyloidosis in Malaysians. Australas J Dermatol. 1991;32(1):39-44. DOI: https:// doi. org/10. 1111/j.1440-0960.1991. tb 00681.x

13. Wang WJ, Chang YT, Huang CY, Lee DD. Clinical and histopathological characteristics of primary cutaneous amyloidosis in 794 Chinese patients. Zhonghua Yi Xue Za Zhi (Taipei). 2001;64(2):101-7. 
14. Al-Ratrout JT, Satti MB. Primary localized cutaneous amyloidosis: a clinicopathologic study from Saudi Arabia. Int J Dermatol. 1997;36(6):428-34.

15. Ratz JL, Bailin PL. Cutaneous amyloidosis: A case report of the tumefactive variant and a review of the spectrum of clinical presentations. J Am Acad Dermatol 1981;4: 21-26.

16. Brownstein MH, Helwig EB. The cutaneous amyloidoses. I. Localized forms. Arch Dermatol. 1970; $102(1): 8-19$.

\section{How to cite this article?}

Kulkarni M. A, Patil T, Solanki P.S. A clinicopathological study of primary cutaneous amyloidosis. Trop J Path Micro 2019;5(6):396-402. doi:10.17511/jopm.2019.i06.10. 